\title{
Assessment of Genetic Diversity and Marker-Trait Associations Using Selected Early Maize Inbreds Derived From Local Landraces of Eastern Himalayan Regions
}

\section{E. Lamalakshmi Devi ( $\nabla$ elangbamlama@gmail.com )}

Indian Council of Agricultural Research https://orcid.org/0000-0002-2304-5418

Umakanta Ngangkham

ICAR Research Complex for NEH Region: ICAR Research Complex for North Eastern Hill Region Manipur Centre

Akoijam Ratankumar Singh

ICAR Research Complex for NEH Region: ICAR Research Complex for North Eastern Hill Region

Bhuvaneswari S

ICAR Research Complex for NEH Region: ICAR Research Complex for North Eastern Hill Region Manipur Centre

\section{Konsam Sarika}

ICAR Research Complex for NEH Region: ICAR Research Complex for North Eastern Hill Region Manipur Centre

\section{Chongtham Chinglen Meetei}

ICAR Research Complex for NEH Region: ICAR Research Complex for North Eastern Hill Region Manipur Centre

\section{Thokchom Nepolian Singh}

Central Agricultural University

\section{Sunil Kumar Chongtham}

Central Agricultural University College of Agricultural Engineering and Post Harvest Technology

Ch Premabati Devi

ICAR Research Complex for NEH Region: ICAR Research Complex for North Eastern Hill Region Manipur Centre

Irengbam Meghachandra Singh

ICAR Research Complex for NEH Region: ICAR Research Complex for North Eastern Hill Region Manipur Centre

\section{Ravikant Avasthe}

Indian Council of Agricultural Research 


\section{Research Article}

Keywords: Genetic diversity, maize, microsatellite markers, population structure, marker-trait association Posted Date: August 17th, 2021

DOl: https://doi.org/10.21203/rs.3.rs-786599/v1

License: (c) (i) This work is licensed under a Creative Commons Attribution 4.0 International License. Read Full License 


\section{Abstract}

North- Eastern parts of India fall under Eastern Himalayan region and it is a diversity hotspot of many crops including maize. Evaluation of genetic diversity is required to tape the potentiality of genetic resources in any crop improvement programmes. In the present study, genetic diversity at fifty two microsatellite markers were conducted in 30 early maize inbreds developed from local landraces of $\mathrm{NE}$ India. Genetic diversity analysis revealed a total of 189 alleles with a mean of 3.63 alleles/ locus. The allele size ranged from $50 \mathrm{bp}$ (phi 036) to $295 \mathrm{bp}$ ( $p$ 101049) which revealed a high level of genetic diversity among the loci. The PIC among the 30 genotypes ranged from 0.17 (umc 1622) to 0.76 (umc 1153) with an average value of 0.49 . The value of Expected Heterozygosity $\left(\mathrm{H}_{\mathrm{Exp}}\right)$ ranged from 0.19 to 0.80 with an average of 0.57 , whereas the Observed Heterozygosity $\left(\mathrm{H}_{\mathrm{Obs}}\right)$ ranged from 0 to 0.89 with a mean of 0.14 .The genetic dissimilarity between the genotype pairs ranged from 0.40 to 0.64 with a mean value of 0.57 . Cluster analysis grouped the 30 inbreds into distinct three sub-clusters. Similarly, population structure and principal coordinate analysis) analysis also classified the 30 inbred lines into three-subpopulations. AMOVA revealed that $6 \%$ of total variance is due to differences among populations, while $94 \%$ of total molecular variance is accounted by within populations. Marker-trait associations showed a total of twelve SSR markers significantly associated with seven agronomic traits. From the present finding, these results show that the thirty maize inbreds have high genetic diversity which would be useful for choosing promising parents and for making cross combination based on genetic distance and clustering for genetic improvement programmes of maize.

\section{Introduction}

Maize (Zea mays L.) often referred to as "Queen of Cereals" due to its remarkable yield potential and economic value is the world's third most grown cereal crop. It assumes global significance because of its versatility in utilization such as human food, livestock feed and as raw materials for several agro-based industries (Choudhary et al. 2015). Eastern Himalayan region mainly North- Eastern region of India is a diversity hub for many crops including maize. There are diverse maize germplasm found in this region. Maize in this region acquired different unique characters like coloured grain having different range from purple, blue, black, white, cream, yellow, orange, red and variegated; multi- cob bearing (3-6 cobs per plant) and waxiness having high amylopectin content. In addition to the above traits, this local maize has high potential as fodder due to its vigorous growth and tillering habit which makes them unique. Local maize has tremendous morphologically variability such as plant height, plant type, duration, kernel colour, texture, nutrient composition, appearance, etc. (Ratankumar et al. 2019). The plant type of local landraces ranged from wild primitive type to advanced landraces/varieties maintained and selected by farmers from time immemorial. The weather conditions in North Eastern region (NER) of India are erratic; drought and floods are common phenomenon in the region. The local germplasm were evolved in balance with the prevalent agro-ecological conditions of the region and, therefore, they are expected to possess better adaptation to regional stresses. 
Availability of wide genetic variability is a pre-requisite for undertaking a successful crop improvement programme. For undertaking breeding program of crop plants, characterization of genotypes, assessment of molecular diversity and studies of genetic relationship is a must (Bharadwaj 2018). Indigenous germplasm have been given preferential for the development of mapping populations, heterotic pools and inbreds (Yadav et al. 2015). Such inbreds can be used as parental lines in development of hybrids, which has potentially enhanced yield than those of local landraces. Characterization of inbreds and their information on genetic diversity and genotype relationships are of utmost importance in any crop improvement programme (Sserumaga et al. 2014; Zunjare et al. 2015; Devi et al. 2017b). Assessment of genetic diversity and inclusion of diverse parents in the breeding programme enhances the chance of achieving more heterotic $\mathrm{F}_{1} s$ and in producing more variable segregants (Devi et al. 2015a).Further, genetic improvement of local germplasm and its utilization in various breeding programmes will be better option as compare to exotic lines due to its wide adaptability to the local ecologies. Therefore, the present study was undertaken to develop inbred lines from local germplasm and to assess genetic diversity, relationships and population structure of the early inbreds developed using SSR markers.

\section{Materials And Methods}

\section{Plant materials}

A set of 30 indigenous $3^{\text {rd }}$ generation early inbred lines of maize were selected for molecular characterization and assessing the genetic diversity. These early lines were developed at ICAR Research Complex for North Eastern Hill Region, Manipur Centre using local germplasm collected from different places of Manipur and Mizoram states of India.

\section{Agronomic performance of inbreds}

Each of the 30 maize inbreds was grown in two rows of $3 \mathrm{~m}$ length each during kharif 2019 at ICAR-RCNEH Region, Manipur Centre Research Farm under standard package of practices for maize cultivation. The row to row and plant to plant distance was maintained at $60 \mathrm{~cm}$ and $20 \mathrm{~cm}$, respectively. The individual plants were carefully selfed and harvested to avoid contamination of inbreds. These early inbreds were evaluated for plant height (PH), ear height (EH), number of kernel rows per ear (KRPE), number of kernels per row (KPR), cob length (CL), cob diameter (CD) and 100 kernel weight (KW).

\section{Genomic DNA isolation and PCR amplification}

Genomic DNA was extracted from the leaf of the selected genotypes using modified CTAB extraction protocol (Porebski et al.1997). DNA concentration was measured on Genova Nano Analyzer UV/VIS (Mumbai, India). Final concentration of extracted genomic DNA was made to $10 \mathrm{ng} / \mu \mathrm{L}$ and used for the PCR amplification. A set of 52 Simple Sequence Repeats' (SSR) markers covering the whole genome were used for the present study and their primer sequences were collected from the maize genomic database (http://www.maizegdb.org/). The oligonucleotide primers were synthesized in purified and lyophilized form from GCC Biotech India Pvt Ltd. (Kolkata, India). 
Polymerase chain reactions were carried out on 96-well thermal cycler, Eppendorf- Mastercycler Nexus Gradient (Hamburg, Germany). All PCRs were performed in a final reactionvolume of $20 \mu \mathrm{Lwith}$ the following reagent components: $2 \mu \mathrm{L}$ of template DNA (20 ng/ $\mu \mathrm{L}), 10 \mu \mathrm{L} 2 \mathrm{X}$ Hi-Primer Taq PCR Master Mix (GCC Biotech India Pvt Ltd., India), $1 \mu \mathrm{L}$ of each forward and reverse primers and $6 \mu \mathrm{L}$ RNA grade nuclease free water (GCC Biotech India Pvt Ltd., India). The amplification conditions were set as follows: initial denaturation at $95^{\circ} \mathrm{C}$ for $5 \mathrm{~min}, 4$ cycles consisting of denaturation at $95^{\circ} \mathrm{C}$ for $45 \mathrm{sec}$, primer annealing ranged between 57 to $60^{\circ} \mathrm{C}$ for $45 \mathrm{sec}$, primer extension at $72^{\circ} \mathrm{C}$ for $45 \mathrm{sec}$ and then $35 \mathrm{cycles}$ consisting of denaturation at $95^{\circ} \mathrm{C}$ for $45 \mathrm{sec}$, primer annealing $60^{\circ} \mathrm{C}$ for $45 \mathrm{sec}$, primer extension at $72^{\circ} \mathrm{C}$ for $45 \mathrm{sec}$ and final extension at $72^{\circ} \mathrm{C}$ for $8 \mathrm{~min}$. The amplified PCR products were resolved using $3.0 \%$ ISSR Agarose (GCC Biotech India Pvt Ltd., India) stained with Ethidium Bromide, documented under gel doc system (Gel Doc ${ }^{T M}$ XR+, Biorad, India).

\section{Statistical analyses}

The genotypic data of 52 SSR markers were used for estimation of genetic diversity parameters such as number of alleles per locus $(K)$, Observed Heterozygosity $\left(H_{O b s}\right)$, Expected Heterozygosity $\left(H_{\text {Exp }}\right)$ and Polymorphic Information Content (PIC) using the Cervus 3.0 program (Field Genetics Ltd., London, England). GenAlEx 6.502 software (Peakall and Smouse 2012) was used to compute the PCoA (Principal Coordinate Analysis) by plotting the eigenvector values in a scatter graph taking the first principal component and the second principal component as the axes. A hierarchical analysis of molecular variance (AMOVA) of 30 genotypes between the populations was also conducted using GenAlEx 6.502 software (Peakall and Smouse 2012). To determine the presence of the genetic structure, STRUCTURE version 2.3.4 (Pritchard et al. 2000) was run with the number of clusters from $K=1$ to $K=5$, with 5 independent replications per $\mathrm{K}$ using the admixture model and correlated allele frequencies, a 50,000 burn-in period and 50,000 MCMC to determine approximations of posterior distributions. The optimum $\mathrm{K}$ value was determined through the STRUCTURE HARVESTER programme (Earl and Vonholdt, 2012) by estimating the peak value of $\triangle \mathrm{K}$ using Evanno et al. (2005) method. The STRUCTURE analyses give a Qmatrix (QST) for each value of $K$, which lists the estimated membership coefficients for each genotype in each subgroup. An individual having more than $70 \%$ of its genome fraction value under a particular $\mathrm{K}$ subgroup was assigned to that subgroup. The allele size was evaluated by comparing with 100 bp DNA ladder (GCC Biotech India Pvt Ltd., India)and a phylogenetic tree was constructed using NeighbourJoining method implemented in DARwin-6.0 (Perrier and Jacquemoud- Collet (2006).

All the statistical analysis of agronomic data was carried out using XLSTAT v2020.4.1 software (www.xlstat.com). The association analysis of seven agronomic traits along with the 52 SSR markers was calculated using GGT 2.0 software (Van Berloo 2008). The association analysis was calculated based on the squared correlation coefficients between the marker data and trait values ( $R^{2}$ values) and the associated probabilities of the correlation values. The threshold to declare a significant marker-trait associations was set to $-\log 10(p)=3$.

\section{Results And Discussion}




\section{Genetic diversity of maize inbreds}

In the present study, all the 52 markers were successfully amplified in 30 maize inbred lines (Fig. 1). A total of 189 alleles were generated across the 30 genotypes with a mean of 3.63 alleles per locus (Table 1). The allele size of the 52 SSR markers ranged from $50 \mathrm{bp}$ (phi 036) to $295 \mathrm{bp}$ ( $p$ 101049) which revealed a high level of genetic diversity among the loci. Several researchers, viz., Hung et al. (2012) [117 alleles, 3.26 average alleles/ locus], Yu et al. (2012) [60 alleles, 2.73 average alleles/ locus], Devi et al. (2017b) [203 alleles, 2.69 average alleles/ locus] observed similar result while working on genetic diversity of maize genotypes. The high number of alleles per locus is most likely attributable to the higher genetic diversity of the lines. The PIC of the markers refers to the relative value of each marker regarding the amount of polymorphism exhibited, ranged from 0.17 (umc 1622) to 0.76 (umc 1153) with an average value of 0.49 demonstrating the high discriminatory power of these markers among the 30 genotypes (Table 1). Out of the 52 SSR markers, 24 SSR loci (46.15\%) were found to be more informative by having of PIC value of $\geq 0.50$, depicting the higher capability of these loci to differentiate between the genotypes, determine genetic diversity, gene introgression, genetic conservation, etc. Genetically diverse genotypes will have higher value of PIC, whereas closely related lines will have lower value (Muthusamy et al. 2015; Devi et al. 2017b). The PIC value of $0.46,0.31$ and 0.40 was also observed by Hung et al. (2012), Hao et al. (2015) and Devi et al. (2017b), respectively. The number of alleles per locus (K) ranged from 2 to 8 with an average of $3.634 \pm 1.428$. The bnlg1031 marker mapped at 8.06 bin showed the highest number of alleles (8). The value of Expected Heterozygosity $\left(H_{\text {Exp }}\right)$ ranged from 0.19 to 0.80 , whereas the Observed Heterozygosity $\left(\mathrm{H}_{\mathrm{Obs}}\right)$ ranged from 0 to 0.89 , indicating that further generations of inbreeding are required to stabilize the inbreds. The presence of high heterozygosity in some of the loci like umc 1354 (0.89), bnlg 2162 (0.79), bnlg 1031 (0.73), umc 2064 (0.57), bnlg 565 (0.39), bnlg 2291 (0.34), umc 2252 (0.33), bnlg 1496 (0.29), bnlg 1601 (0.27), etc. indicated the needs for further inbreeding in order to stabilise the lines. Hung et al. (2012) also reported high heterozygosity in his study among waxy maize inbreds. 
Table 1

Genetic diversity analysis for 52 SSR markers in 30 genotypes

\begin{tabular}{|c|c|c|c|c|c|c|}
\hline $\begin{array}{l}\text { SI } \\
\text { No. }\end{array}$ & Locus & $\begin{array}{l}\text { Bin } \\
\text { location }\end{array}$ & $\mathrm{K}$ & $\mathrm{H}_{\mathrm{Obs}}$ & $\mathrm{H}_{\operatorname{Exp}}$ & PIC \\
\hline 1 & umc 1354 & 1.00 & 6 & 0.89 & 0.71 & 0.66 \\
\hline 2 & umc 1685 & 1.01 & 2 & 0.03 & 0.50 & 0.37 \\
\hline 3 & umc 2225 & 1.02 & 4 & 0.07 & 0.59 & 0.50 \\
\hline 4 & bnlg 2238 & 1.04 & 5 & 0.07 & 0.66 & 0.59 \\
\hline 5 & umc 2064 & 1.07 & 4 & 0.57 & 0.75 & 0.69 \\
\hline 6 & umc 1622 & 1.12 & 3 & 0 & 0.19 & 0.17 \\
\hline 7 & bnlg 1064 & 2.03 & 3 & 0.2 & 0.56 & 0.47 \\
\hline 8 & umc 2007 & 2.04 & 5 & 0.03 & 0.68 & 0.61 \\
\hline 9 & umc 2252 & 2.05 & 3 & 0.33 & 0.44 & 0.37 \\
\hline 10 & bnlg 2077 & 2.07 & 4 & 0.15 & 0.75 & 0.69 \\
\hline 11 & umc 2085 & 2.08 & 2 & 0 & 0.51 & 0.37 \\
\hline 12 & P 101049 & 2.10 & 5 & 0.07 & 0.68 & 0.61 \\
\hline 13 & phi 036 & 3.04 & 5 & 0.21 & 0.74 & 0.67 \\
\hline 14 & bnlg 1601 & 3.05 & 4 & 0.27 & 0.72 & 0.66 \\
\hline 15 & umc 2050 & 3.07 & 2 & 0.14 & 0.46 & 0.35 \\
\hline 16 & umc2174 & 3.08 & 2 & 0.05 & 0.34 & 0.28 \\
\hline 17 & bnlg 1496 & 3.09 & 6 & 0.29 & 0.74 & 0.68 \\
\hline 18 & umc 1008 & 4.00 & 2 & 0 & 0.51 & 0.37 \\
\hline 19 & umc 2410 & 4.02 & 3 & 0.03 & 0.62 & 0.54 \\
\hline 20 & umc 1117 & 4.04 & 3 & 0 & 0.67 & 0.58 \\
\hline 21 & bnlg 2291 & 4.06 & 3 & 0.34 & 0.52 & 0.45 \\
\hline 22 & bnlg2162 & 4.08 & 5 & 0.79 & 0.77 & 0.71 \\
\hline 23 & umc 2289 & 4.10 & 5 & 0.13 & 0.64 & 0.56 \\
\hline 24 & umc 1305 & 5.00 & 4 & 0.07 & 0.35 & 0.32 \\
\hline 25 & bnlg 565 & 5.02 & 5 & 0.39 & 0.76 & 0.71 \\
\hline 26 & umc 2304 & 5.05 & 4 & 0.18 & 0.47 & 0.41 \\
\hline
\end{tabular}




\begin{tabular}{|c|c|c|c|c|c|c|}
\hline $\begin{array}{l}\text { SI } \\
\text { No. }\end{array}$ & Locus & $\begin{array}{l}\text { Bin } \\
\text { location }\end{array}$ & $\mathrm{K}$ & $\mathrm{H}_{\mathrm{Obs}}$ & $\mathrm{H}_{\mathrm{Exp}}$ & PIC \\
\hline 27 & umc 1225 & 5.08 & 5 & 0.1 & 0.79 & 0.74 \\
\hline 28 & umc 1686 & 5.03 & 2 & 0 & 0.50 & 0.37 \\
\hline 29 & umc 1153 & 5.09 & 6 & 0 & 0.80 & 0.76 \\
\hline 30 & umc 1002 & 6.00 & 2 & 0 & 0.49 & 0.36 \\
\hline 31 & umc 2318 & 6.05 & 2 & 0 & 0.44 & 0.34 \\
\hline 32 & umc 1257 & 6.02 & 3 & 0 & 0.55 & 0.45 \\
\hline 33 & umc 1912 & 6.06 & 5 & 0 & 0.70 & 0.64 \\
\hline 34 & bnlg 1740 & 6.07 & 5 & 0.22 & 0.63 & 0.58 \\
\hline 35 & umc 1642 & 7.00 & 4 & 0 & 0.61 & 0.51 \\
\hline 36 & umc 2325 & 7.01 & 2 & 0 & 0.48 & 0.36 \\
\hline 37 & $\begin{array}{l}\mathrm{mmc} \\
0411\end{array}$ & 7.03 & 3 & 0.22 & 0.56 & 0.45 \\
\hline 38 & umc 1154 & 7.05 & 2 & 0.04 & 0.40 & 0.31 \\
\hline 39 & umc 1543 & 7.04 & 2 & 0 & 0.34 & 0.27 \\
\hline 40 & umc 1932 & 7.02 & 2 & 0 & 0.46 & 0.35 \\
\hline 41 & umc 2042 & 8.01 & 2 & 0 & 0.50 & 0.37 \\
\hline 42 & bnlg 1194 & 8.02 & 4 & 0.36 & 0.72 & 0.65 \\
\hline 43 & bnlg 1031 & 8.06 & 8 & 0.30 & 0.73 & 0.68 \\
\hline 44 & umc 1607 & 8.07 & 2 & 0 & 0.41 & 0.32 \\
\hline 45 & bnlg 1012 & 9.04 & 3 & 0 & 0.58 & 0.49 \\
\hline 46 & bnlg 1091 & 9.05 & 4 & 0.12 & 0.58 & 0.49 \\
\hline 47 & umc 1380 & 10.00 & 3 & 0.13 & 0.56 & 0.46 \\
\hline 48 & umc 1576 & 10.02 & 2 & 0 & 0.47 & 0.36 \\
\hline 49 & umc 1962 & 10.03 & 5 & 0.23 & 0.44 & 0.40 \\
\hline 50 & umc 1506 & 10.05 & 4 & 0 & 0.62 & 0.54 \\
\hline 51 & bnlg2190 & 10.06 & 5 & 0.07 & 0.65 & 0.58 \\
\hline 52 & umc 2021 & 10.07 & 3 & 0.17 & 0.55 & 0.46 \\
\hline
\end{tabular}




\begin{tabular}{|c|c|c|c|c|c|}
\hline Locus & $\begin{array}{l}\text { Bin } \\
\text { location }\end{array}$ & $\mathrm{K}$ & $\mathrm{H}_{\mathrm{Obs}}$ & $\mathrm{H}_{\mathrm{Exp}}$ & PIC \\
\hline Mean \pm SD & & $\begin{array}{l}3.634 \pm \\
1.428\end{array}$ & $\begin{array}{l}0.139 \pm \\
0.193\end{array}$ & $\begin{array}{l}0.574 \pm \\
0.137\end{array}$ & $\begin{array}{l}0.493 \pm \\
0.146\end{array}$ \\
\hline
\end{tabular}

The heterozygosity percentage of the inbred lines at 52 SSR markers was studied which revealed the range of heterozygosity from 0 (SCM 15/9LC) to 27.45 (GP H 6) (Table 2). The graphical representations of heterozygosity in 30 maize inbreds are depicted in Fig. 2. Out of 30 inbred lines, 13 lines showed heterozygosity $\leq 10 \%$, which means $43 \%$ of the lines attained more than $90 \%$ homozygosity. Another 3 inbred lines viz. GP (H) 38, MN 1 and SCM15/9LC showed heterozygosity less than $5 \%$, which revealed a high level of homozygosity in these lines. These three inbred maize lines may be considered as pure lines which will be useful for development of mapping populations, genetic mapping, etc. Analysis of molecular variance (AMOVA) is an efficient way to assess overall distribution of diversity within and among populations (Belalia et al. 2019). In the present study, the AMOVA result revealed a higher molecular variance within individuals of population than among individuals of population. Similar findings were reported by Prasanna (2012), Silva et al. (2015) and Belalia et al. (2019). 
Table 2

Population structure group and heterozygosity (\%) of 30 early inbred lines

\begin{tabular}{|c|c|c|c|c|c|c|}
\hline SI No. & Genotypes & Heterozygosity (\%) & Q1 & Q2 & Q3 & Structure groups \\
\hline 1 & MZ 44 (c) & 14.28 & 0.0060 & 0.0420 & 0.952 & G3 \\
\hline 2 & MZ 13(a) & 8.0 & 0.144 & 0.011 & 0.845 & G3 \\
\hline 3 & MZ 34 (a) & 13.04 & 0.196 & 0.006 & 0.798 & G3 \\
\hline 4 & $\mathrm{GP}(\mathrm{H}) 1$ & 14.58 & 0.024 & 0.017 & 0.959 & G3 \\
\hline 5 & $\mathrm{GP}(\mathrm{H}) 6$ & 27.45 & 0.112 & 0.036 & 0.852 & G3 \\
\hline 6 & MZ $45(A)$ & 10.20 & 0.947 & 0.018 & 0.035 & $\mathrm{G} 1$ \\
\hline 7 & MZ 21 (a) & 8.51 & 0.077 & 0.009 & 0.914 & G3 \\
\hline 8 & MN 17 & 8.69 & 0.609 & 0.344 & 0.046 & $A D$ \\
\hline 9 & GP(H)-2 & 5.12 & 0.036 & 0.009 & 0.956 & G3 \\
\hline 10 & $M Z 41(A)$ & 6.60 & 0.986 & 0.006 & 0.008 & $\mathrm{G} 1$ \\
\hline 11 & MZ 46 (B ) & 16.67 & 0.905 & 0.011 & 0.084 & $\mathrm{G} 1$ \\
\hline 12 & GP $(H) 38$ & 4.25 & 0.988 & 0.004 & 0.008 & $\mathrm{G} 1$ \\
\hline 13 & Kolasib1(2) & 20.41 & 0.961 & 0.029 & 0.01 & $\mathrm{G} 1$ \\
\hline 14 & MN 30 & 6.12 & 0.022 & 0.003 & 0.975 & G3 \\
\hline 15 & MN 12 & 6.52 & 0.988 & 0.008 & 0.004 & $\mathrm{G} 1$ \\
\hline 16 & MZ 42 & 8.33 & 0.956 & 0.007 & 0.037 & $\mathrm{G} 1$ \\
\hline 17 & MZ 40 & 14.00 & 0.956 & 0.006 & 0.038 & $\mathrm{G} 1$ \\
\hline 18 & MZ 70 & 20.41 & 0.983 & 0.004 & 0.013 & $\mathrm{G} 1$ \\
\hline 19 & MZ 24 & 10.41 & 0.965 & 0.028 & 0.007 & G1 \\
\hline 20 & MZ 2 & 11.53 & 0.991 & 0.005 & 0.004 & G1 \\
\hline 21 & MN 29 & 10.0 & 0.005 & 0.902 & 0.092 & $\mathrm{G} 2$ \\
\hline 22 & MN 1 & 3.92 & 0.005 & 0.992 & 0.003 & $\mathrm{G} 2$ \\
\hline 23 & SCM 15/9LC & 0 & 0.012 & 0.948 & 0.039 & $\mathrm{G} 2$ \\
\hline 24 & MZ 56 (a) & 6.38 & 0.022 & 0.972 & 0.006 & $\mathrm{G} 2$ \\
\hline 25 & MZ 48 & 14.89 & 0.006 & 0.986 & 0.007 & $\mathrm{G} 2$ \\
\hline 26 & MZ 29 & 8.33 & 0.003 & 0.017 & 0.981 & G3 \\
\hline
\end{tabular}




\begin{tabular}{|lllllll|}
\hline SI No. & Genotypes & Heterozygosity (\%) & Q1 & Q2 & Q3 & Structure groups \\
\hline 27 & MN 13 & 12.76 & 0.01 & 0.951 & 0.038 & G2 \\
\hline 28 & MN 3 & 14.0 & 0.003 & 0.994 & 0.003 & G2 \\
\hline 29 & GP(H) 28 & 7.84 & 0.008 & 0.931 & 0.061 & G2 \\
\hline 30 & MZ 22 & 6.38 & 0.207 & 0.759 & 0.034 & G2 \\
\hline AD: Admixture & & & & & \\
\hline
\end{tabular}

\section{Genetic Relationships Analysis Among Early Maize Inbreds}

The genotypic data of 52 SSR markers were used to estimate genetic distance matrix and a corresponding dendrogram was developed. Cluster analysis of 30 early maize inbred lines developed from local landraces was conducted based on genetic dissimilarities from SSR data using neighbourjoining method. The genetic dissimilarity between the genotype pairs ranged from 0.40 to 0.64 with a mean value of 0.57 . Cluster diagram grouped the 30 maize genotypes into three distinct major clusters viz., A, B and C (Fig. 3). Cluster A comprised of 3 genotypes viz., GP(H) 2, GP(H) 28 and SCM15/9LC and was further sub divided into 2 sub- groups (A1; GP(H) 2 and A2; GP(H) 28 and SCM15/9LC). Another cluster, $\mathrm{B}$ holds the highest number of genotypes i.e. 24 with three sub- groups viz. B1, B2 and B3. B1, B2 and $B 3$ comprised of 13, 3 and 8 genotypes, respectively. There were only 3 genotypes under cluster $C$ which comprised of inbreds MZ 21(A), MN 30 and MZ 29.

To established genetic relationships among the 30 maize inbred lines based on 52 SSR markers, the PCoA (Principal Coordinate Analysis) using GenAlEx 6.502 software was constructed. The genotypic PCoA revealed that the lines were distributed in all the four quadrangles, showing high degree of genetic variability. A scatter plot generated from the PCoA analysis showed that the first two components accounted for $9.82 \%$ and $8.23 \%$ of the genetic variation which resulted in a total genetic variation of $18.05 \%$ (Fig. 4). Similar works on genetic relationship analysis in maize were also reported by Choudhary et al. 2015, Muthusamy et al. 2015 and Devi et al. 2017b.

\section{Population Structure Analysis And Allelic Patterns Across Populations}

The genotypic data of 52 SSR markers were also used to determine the population structure in 30 maize inbred lines using STRUCTURE software. Using STRUCTURE HARVESTER program, the peak plateau of ad hoc measure $\Delta K$ was detected at $K=3$, which indicated that the entire population can be grouped into three subgroups (Fig. 5).

Population structures of 30 genotypes based on 52 SSR markers are shown in Fig. 5. Different colour within group indicates the proportion of shared ancestry with other group which has the same colour with the admixture. The population structure group of 30 genotypes based on inferred ancestry values were also estimated (Table 2). The percentage of individuals in each population belonging to each group were estimated based on Q-matrix (QST) for each value of K and the cut off probability for assigning to a 
group was assumed to be $70 \%$. A set of 29 genotypes out of 30 showed the estimated membership coefficients of more than $70 \%$ of its genome fraction value and were therefore assigned to a specific group. Whereas, only one genotype was classified as admixture since it showed the estimated membership coefficients of less than $70 \%$. This revealed that almost all the genotypes under study are not admixture. In the present study, only one inbred was under the category of admixture, indicating that it is of mixed pedigree, possibly because of introgression of gene(s) while developing the inbred line (Yin et al., 2019). Group 1 consisted of 11 genotypes out of which 9 (MZ 45 (A), MZ 41 (A), MZ 46 (B), Kolasib 1 (2), MZ 42, MZ 40, MZ 70, MZ 24 and MZ 2) genotypes have originated from Mizoram and only 2 (GP(H) 38 and $M N$ 12) genotypes from Manipur. Group 2 gathered 9 genotypes out of which 6 genotypes (MN 29, MN 1, SCM15/9LC, MN 13, MN 3 and GP (H) 28) originated from Manipur and only 3 genotypes (MZ 56 (A), MZ 48 and MZ 22) have origin in Mizoram. Group 3 has 9 genotypes out of which 5 are originated in Mizoram (MZ 44 (C), MZ 13 (A), MZ 34 (A), MZ 21 (A) and MZ 29) and 4 from Manipur (GP (H) 1, GP (H) 6, GP (H) 2 and $M N 30$.

In depth knowledge of genetic diversity and population structure of maize would have a big impact on maize improvement program (Liu et al., 2003). The clustering pattern of all the genotypes based on marker information was found to have a close correlation with their pedigree information. The 30 early inbreds were developed from several populations collected from two north- eastern States of India i.e., Manipur and Mizoram. The lines developed from same source population from Manipur fall under same cluster/ sub- cluster while those developed from Mizoram also fall under same cluster/ sub- cluster. For instance, lines developed from populations collected from Manipur viz. GP (H) 2, GP (H) 28 and SCM 15/9LC were together in same cluster i.e., A. Likewise, lines like MZ 2, MZ 70, MZ 24, MZ 42, MZ 40, Kolasib 1(2), MZ 46(B), etc. developed from populations collected from Mizoram clustered together in same sub- group viz., B1. Lines derived from the populations from Manipur were found to be closely placed in genotypic PCoA, while that from Mizoram occupied the nearby axes in the PCoA. To conduct the analysis of molecular variance (AMOVA), the 30 maize inbred lines were grouped into two: Manipur (developed from Manipur collection) and Mizoram (developed lines using Mizoram collection). AMOVA revealed highly significant variance among populations and within individuals of population (Table 3 ). The overall genetic differentiation indicated that $6 \%$ of total variance is due to differences among populations, while $94 \%$ of total molecular variance is accounted by within population molecular variance (Fig. 5). 
Table 3

Results of analysis of molecular variance (AMOVA) between the two populations

\begin{tabular}{|llllll|}
\hline Source & df & SS & MS & Est. Var. & Percentage of variation \\
\hline Among Pops & 1 & 0.316 & 0.316 & 0.010 & 6 \\
\hline Within Pops & 28 & 4.751 & 0.170 & 0.170 & 94 \\
\hline Total & 29 & 5.067 & & 0.180 & 100 \\
\hline $\begin{array}{l}\text { df: degree of freedom; SS: sum of squares; MS: mean squares; Est. Var. = estimated variance }(P \text { value } \\
>0.001)\end{array}$
\end{tabular}

The mean effective numbers of allele ( $\mathrm{Ne}$ ) were estimated to be 2.31 and 3.99 for Manipur (MAN) and Mizoram (MIZ) population, respectively (Table 4). The number of alleles (allelic richness) in a population is an important and fundamental measure of genetic variation in a population, and is a useful statistic for identifying populations for conservation (Kalinowski 2004). The Shannon's information index (I) was calculated as 0.96 and 1.58 for MAN and MIZ population, respectively. Among 189 alleles generated across the 30 genotypes, 3 private alleles (number of alleles unique to a single population) were detected in SSR marker umc 1354. These private alleles were revealed in 3 genotypes originated from Mizoram. The mean values of population parameters such as allelic richness/ number of different alleles $(\mathrm{Na})$, number of different alleles with a frequency $>=5 \%$ (Na FrEq. >= 5\%), expected Heterozygosity $(\mathrm{He})$ and Unbiased expected Heterozygosity (uHe) were also estimated (Table 4). The results of this study provides useful information to maize breeders for selection of inbred lines and for making promising cross combinations based on genetic distance and clustering. 


\section{Mean values}

\begin{tabular}{lll} 
Population & MAN & MIZ \\
$\mathrm{Na}$ & 3.000 & 6.000 \\
$\mathrm{Na} \mathrm{FrEq.}>=5 \%$ & 3.000 & 6.000 \\
$\mathrm{Ne}$ & 2.305 & 3.986 \\
$\mathrm{I}$ & 0.958 & 1.575 \\
\hline No. Private Alleles & 0.000 & 3.000 \\
$\mathrm{He}$ & 0.566 & 0.749 \\
$\mathrm{uHe}$ & 0.593 & 0.772
\end{tabular}

$\mathrm{Na}=$ No. of Different Alleles

$\mathrm{Na}($ Freq $>=5 \%)=$ No. of Different Alleles with a Frequency $>=5 \%$

$\mathrm{Ne}=$ No. of Effective Alleles $=1 /($ Sum pi^2)

$I=$ Shannon's Information Index $=-1$ * Sum (pi * Ln (pi)

No. Private Alleles $=$ No. of Alleles Unique to a Single Population

No. LComm Alleles $(<=25 \%)=$ No. of Locally Common Alleles (FrEq. $>=5 \%$ ) Found in $25 \%$ or Fewer Populations

No. LComm Alleles $(<=50 \%)=$ No. of Locally Common Alleles (FrEq. $>=5 \%)$ Found in $50 \%$ or Fewer Populations

$\mathrm{He}=$ Expected Heterozygosity $=1-$ Sum $\mathrm{pi}^{\wedge} 2$

$\mathrm{uHe}=$ Unbiased Expected Heterozygosity $=(2 \mathrm{~N} /(2 \mathrm{~N}-1)) * \mathrm{He}$

\section{Agro-Morphological Diversity And Marker-Trait Association}

The statistical parameters (mean, standard deviation and correlation coefficients) related to agromorphological traits of the lines are presented in Tables 5 and 6.The plant height $(\mathrm{cm})$ ranged from 172.00- 286.67 with a mean and standard deviation of 225.88 and 29.68 , respectively. The ear height $(\mathrm{cm})$ was recorded between $44.50-170.00$ with a mean and standard deviation of 104.18 and 27.70, respectively. For number of kernel rows per ear, the minimum range was 8.83 and maximum was 16.67 with a mean and standard deviation of 12.45 and 1.73, respectively. The number of kernel per row was estimated between 9.50-54.72 with a mean and standard deviation of 20.78 and 8.16 , respectively. The cob length $(\mathrm{cm})$ ranged from 8.75- 17.00 with a mean value and standard deviation of 12.99 and 2.25, respectively. The cob diameter $(\mathrm{cm})$ and 100 kernel weights $(\mathrm{g})$ had recorded minimum value of 1.30 and 
14.62 and maximum value of 3.32 and 32.42 , respectively with a mean and standard deviation of 2.46 and 22.12 and 0.47 and 4.50 , respectively. A positive correlation was found between some important agronomic traits (Table 6). The highest and positive significant correlation was observed between $\mathrm{PH}$ and $\mathrm{EH}(r=0.76)$, followed by CD and KW $(r=0.46), \mathrm{PH}$ and KW $(r=0.38), \mathrm{CL}$ and KW $(r=0.37)$ and $\mathrm{EH}$ and $\operatorname{KRPE}(r=0.37)$.

Table 5

Descriptive statistics of seven traits in the 30 early maize inbreds used in the study

\begin{tabular}{|llllllll|}
\hline Statistic & PH & EH & KRPE & KPR & CL & CD & KW \\
\hline Minimum & 172.000 & 44.500 & 8.833 & 9.500 & 8.750 & 1.300 & 14.623 \\
\hline Maximum & 286.667 & 170.000 & 16.667 & 54.720 & 17.000 & 3.320 & 32.423 \\
\hline Mean & 225.876 & 104.177 & 12.455 & 20.782 & 12.993 & 2.465 & 22.119 \\
\hline Standard deviation & 29.683 & 27.695 & 1.726 & 8.158 & 2.247 & 0.472 & 4.498 \\
\hline
\end{tabular}

Table 6

Estimation of correlation coefficients at seven agronomic traits in the 30 early maize inbred lines used.

\begin{tabular}{|lllllll|}
\hline Traits & EH & KRPE & KPR & CL & CD & KW \\
\hline PH & $\mathbf{0 . 7 5 8 * * *}$ & 0.093 & -0.023 & 0.342 & 0.263 & $\mathbf{0 . 3 7 9 *}$ \\
\hline EH & & $0.371 *$ & 0.074 & 0.075 & 0.188 & 0.175 \\
\hline KRPE & & 0.233 & 0.004 & 0.290 & -0.186 \\
\hline KPR & & & 0.292 & 0.183 & 0.005 \\
\hline CL & & & & 0.265 & $\mathbf{0 . 3 7 4 *}$ \\
\hline CD & & & & & $0.463^{* *}$ \\
\hline * ** \& *** Significance at P value $0.001,0.01 \& 0.05$ respectively \\
\hline
\end{tabular}

In the present study, significant marker- trait associations were conducted between the SSR markers and the 7 agro- morphological traits (Table 7). The lowest $\mathrm{R}^{2}$ value $(0.06)$ was detected in umc $1257, \mathrm{mmc}$ 0411, umc 1607 and umc 1002, which was associated with CL, KRPE, CD and KW and the highest (0.21) was in umc 2325, which was associated with KW. The PH was associated with 5 markers viz., umc 1275, umc 1912, mmc 0411, umc 1932 and umc 1962 with $\mathrm{R}^{2}$ value ranged from 0.08-0.13. For EH, the $\mathrm{R}^{2}$ value was ranged from 0.08-0.14 with 3 markers associated with the trait viz., umc 1912, mmc 0411 and umc 1962. The KPR was associated with only 2 markers umc $1153(0.08)$ and umc $2318(0.08)$. The CL was found to be associated with 4 markers viz., umc 1257, mmc 0411, umc 1031 and umc 1506 with ${ }^{2}$ value ranged from 0.06- 0.12 . In case of KRPE, 4 markers were associated with the trait with $\mathrm{R}^{2}$ value that ranged from 0.06-0.20. Likewise, in $C D$ and $K W, 3$ markers were linked with these traits with $R^{2}$ value 
ranging from $0.06-0.07$ and $0.06-0.21$, respectively. The SSR markers identified in the present study may serve as useful molecular markers for selecting important agronomic traits in maize breeding.

Table 7

Association analysis of seven agronomic traits with 52 SSR markers in 30 early maize inbred lines

\begin{tabular}{|c|c|c|c|}
\hline SI No. & Traits & Markers & $R^{2}$ values \\
\hline \multirow[t]{5}{*}{1} & \multirow[t]{5}{*}{ Plant Height (PH) } & Umc1275 & 0.08 \\
\hline & & Umc1912 & 0.13 \\
\hline & & Mmc0411 & 0.11 \\
\hline & & Umc1932 & 0.08 \\
\hline & & Umc1962 & 0.12 \\
\hline \multirow[t]{3}{*}{2} & \multirow[t]{3}{*}{ Ear Height (EH) } & Umc1912 & 0.14 \\
\hline & & Mmc0411 & 0.08 \\
\hline & & Umc1962 & 0.10 \\
\hline \multirow[t]{2}{*}{3} & \multirow[t]{2}{*}{ Number of kernel per row (KPR) } & Umc1153 & 0.08 \\
\hline & & Umc2318 & 0.08 \\
\hline \multirow[t]{4}{*}{4} & \multirow[t]{4}{*}{ Cob Length (CL) } & Umc1257 & 0.06 \\
\hline & & Mmc0411 & 0.06 \\
\hline & & Umc1031 & 0.12 \\
\hline & & Umc1506 & 0.10 \\
\hline \multirow[t]{4}{*}{5} & \multirow[t]{4}{*}{ Number of kernel rows per ear (KRPE) } & Mmc0411 & 0.06 \\
\hline & & Umc2042 & 0.09 \\
\hline & & Umc1962 & 0.20 \\
\hline & & Umc201 & 0.10 \\
\hline \multirow[t]{3}{*}{6} & \multirow[t]{3}{*}{ Cob Diameter (CD) } & Umc1607 & 0.06 \\
\hline & & Umc1543 & 0.07 \\
\hline & & Umc2325 & 0.07 \\
\hline \multirow[t]{3}{*}{7} & \multirow[t]{3}{*}{ Kernel Weight (KW) } & Umc1002 & 0.06 \\
\hline & & Umc1257 & 0.07 \\
\hline & & Umc2325 & 0.21 \\
\hline
\end{tabular}


A high range of variation was found for all the seven agronomic traits which revealed a high level of variation in these lines. The marker- trait association study showed that many markers are associated with the agronomic traits studied and these markers will be useful for selecting lines having good agronomic characteristics. Moreover, these results will be useful in selection of promising inbred lines for use as parents in hybrid breeding program and in marker assisted selection of maize.

\section{Declarations}

Ethical statement: We consciously assure that this manuscript is the authors' own original work, which has not been previously published or is not currently being considered for publication elsewhere.

Acknowledgement: We would like to acknowledge the Director, ICAR- RC- NEH Region, Umiam, Meghalaya, India for the financial support and facilities

Funding: This research was supported by funding from the Indian Council of Agricultural Research under the project "Development of single cross maize hybrid(s) for north eastern hilly states" (PIMS code: IXX13387).

Conflicts of interest/Competing interests: The author(s) declare that they have no competing interests.

Availability of data and material (data transparency): NA

Code availability: NA

Ethics approval (include appropriate approvals or waivers): NA

Consent to participate (include appropriate statements): NA

Consent for publication (include appropriate statements): We, the undersigned, give our consent for the publication of the research paper in the above Journal.

\section{References}

1. Belalia N, Lupini A, Djemel A, Morsli A, Mauceri A, Lotti C, Khelifi-Slaoui M, Khelifi L, Sunseri F (2019) Analysis of genetic diversity and population structure in Saharan maize (Zea mays L.) populations using phenotypic traits and SSR markers. Genet Resour Crop Evol 66:243-257

2. Bharadwaj DN (2018) Advanced molecular plant breeding: meeting the challenge of food security. Apple Academic Press, Florida

3. Choudhary M, Hossain F, Muthusamy V, Thirunavukkarasu N, Saha S, Pandey N, Jha SK, Gupta HS (2015) Microsatellite markerbased genetic diversity analyses of novel maize inbreds possessing rare allele of b-carotene hydroxylase (crtRB1) for their utilization in b-carotene enrichment. J Plant Biochem Biotechnol 25:12-20 
4. Devi EL, Verma SS, Kumar S, Singh NK (2015a) Genetic variability studies for yield and contributing traits under two plant densities and molecular diversity analysis in maize (Zea mays L.). Maydica 60(4):1-11

5. Devi EL, Hossain F, Muthusamy V, Chhabra R, Zunjare RU, Baveja A, Jaiswal SK, Goswami R, Dosad $S(2017 b)$ Microsatellite marker-based characterization of waxy maize inbreds for their utilization in hybrid breeding. 3Biotech7:316 (doi:10.1007/s13205-017-0946-8)

6. Earl DA, Vonholdt BM (2012) STRUCTURE HARVESTER: a website and programfor visualizing STRUCTURE output and implementing theEvanno method. Cons Genet Res 4(2):359-361

7. Evanno G, Regnaut S, Goudet J (2005) Detecting the number of clustersof individuals using the software STRUCTURE: a simulationstudy.MolEcol 14(8):2611-2620

8. Hao D, Zhang Z, Cheng Y, Chen G, Lu H, Mao Y, Shi M, Huang X, Zhou G, Xue L (2015) Identification of genetic differentiation between waxy and common maize by SNP genotyping. PLoS One 10:e0142585. doi:10.1371/journal.pone.0142585

9. Hung TN, Huyen TN, Loc NV, Cuong BM (2012) The application of SSR molecular indicator to assess the purity and genetic diversity of waxy corn inbred lines. J ISSASS 18:45-54

10. Kalinowski ST (2004) Counting Alleles with Rarefaction: Private Alleles and Hierarchical Sampling Designs. Conserv Genet 5:539-543 0

11. Liu K, Goodman M, Muse S, Smith JS, Buckler E, Doebley J (2003) Genetic structure and diversity among maize inbred lines as inferred from DNA microsatellites. Genetics 165:2117-2128

12. Muthusamy V, Hossain F, Thirunavukkarasu N, Pandey N, Vishwakarma AK, Saha S, Gupta HS (2015) Molecular characterization of exotic and indigenous maize inbreds for biofortification with kernel carotenoids. Food Biotechnol 29:276-295

13. Peakall RO, Smouse PE (2012) GenAlex 6.5: genetic analysis in Excel.Population genetic software for teaching and research, 28. Bioinformatics, pp 2537-2539

14. Perrier $X$, Jacquemoud-Collet JP (2006) DARwin software http://darwi n.cirad.fr/darwi n

15. Porebski S, Bailey LG, Baum BR (1997) Modification of a CTAB DNA extraction protocol for plants containing high polysaccharide and polyphenol components. Plant Mol Biol Rep 15:8-15

16. Prasanna BM (2012) Diversity in global maize germplasm: characterization and utilization. J Biosci 37:843-855

17. Pritchard JK, Stephens M, Donnelly P (2000) Inference of populationstructure using multilocus genotype data. Genetics 155(2):945-959

18. Silva TA, Cantagalli LB, Saavedra J, Lopes AD, Mangolin CA, Pires MF, Machado S, Scapim CA (2015) Population structure and genetic diversity of Brazilian popcorn germplasm inferred by microsatellite markers. Electron J Biotech 18:181-187

19. Singh AR, Devi EL, Dayal V, Saha S, Lungmauna, Dutta SK, Boopathi T, Singh SB (2019) Diversity of landraces maize in Mizoram: Prospects, challenges and opportunities. In: (In) Souvenirof National workshop on scientific maize cultivation in north east India. Aizawl, India, pp 98-104 
20. Sserumaga JP, Makumbi D, Ji H, Njoroge K, Muthomi JW, Chemining'wa GN, Si-myung L, Asea G, Kim $\mathrm{H}$ (2014) Molecular characterization of tropical maize inbred lines using microsatellite DNA markers. Maydica 59:267-274

21. vanBerloo R (2008) GGT 2.0: versatile software for visualization and analysis of genetic data. J Hered 99:232-236

22. Yadav OP, Hossain F, Karjagi CG, Kumar B, Zaidi PH, Jat SL, Chawla JS, Kaul J, Hooda KS, Kumar P, Yadava P, Dhillon BS (2015) Genetic Improvement of Maize in India. Retrospect ProspectsAgricultural Research 4(4):325-338

23. Yin V, Sa KJ, Lim SE, Lee JK (2019) Genetic diversity and association analyses of Chinese maize inbred lines using SSR markers. Plant Breed Biotech 7(3):186-199

24. Yu RH, Wang YL, Sun Y, Liu B (2012) Analysis of genetic distance by SSR in waxy maize. Genet Mol Res 11(1):254-260

25. Zunjare R, Hossain F, Muthusamy V, Vishwakarma AK, Pandey N, Kumar P, Sekhar JC, Jha SK, Nepolean T, Gupta HS (2015) Analyses of genetic diversity among exotic- and indigenousmaize inbreds differing for responses to stored grain weevil (Sitophilus oryzae L.) infestation. Maydica $60: 1-7$

\section{Figures}
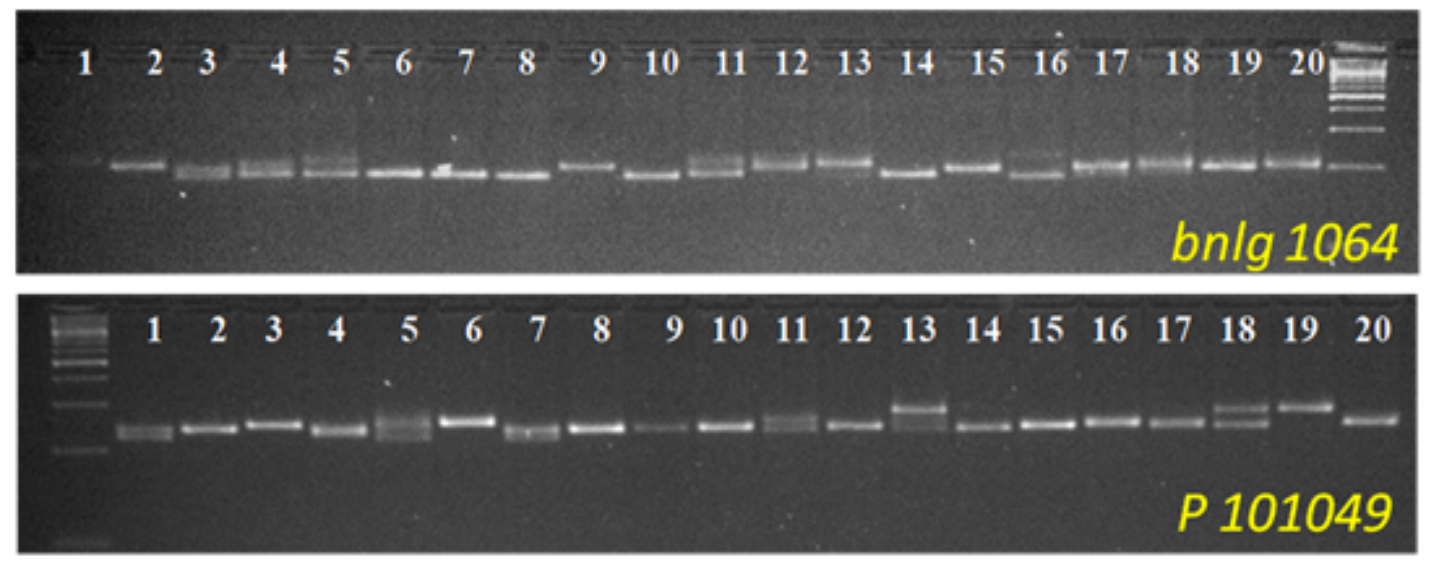

$\begin{array}{llllllllllllllllllll}1 & 2 & 3 & 4 & 5 & 6 & 7 & 8 & 9 & 10 & 11 & 12 & 13 & 14 & 15 & 16 & 17 & 18 & 19 & 20\end{array}$

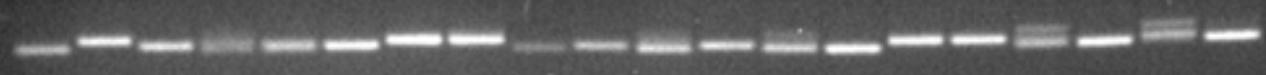

umc 1380

Figure 1 
Representative of gel image showing SSR profiles of 30 early maize inbreds using SSR marker bnlg 1064, p 101049 and umc 1380, respectively. A 100 bp standard DNA ladder was used for size estimation. Lane 1-20 denote maize inbreds)

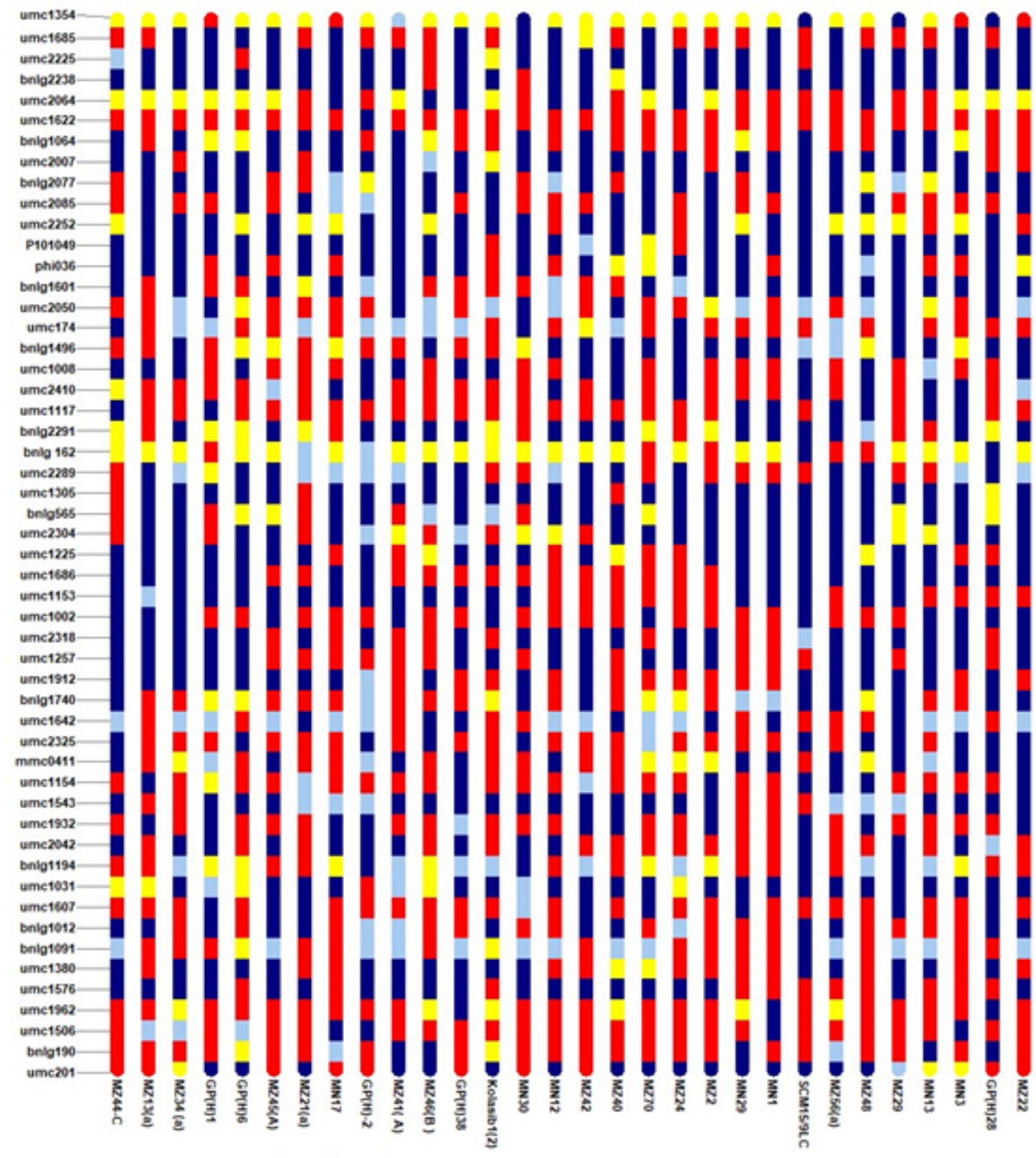

Figure 2

Depiction of allelic patterns of the 52 SSR markers among the 30 early maize inbreds lines through GGT 2.0 software (Van Berloo 2008). The colour legends such as red, purple, yellow and gray denotes A, B, H (heterozygotic) and missing alleles, respectively. 


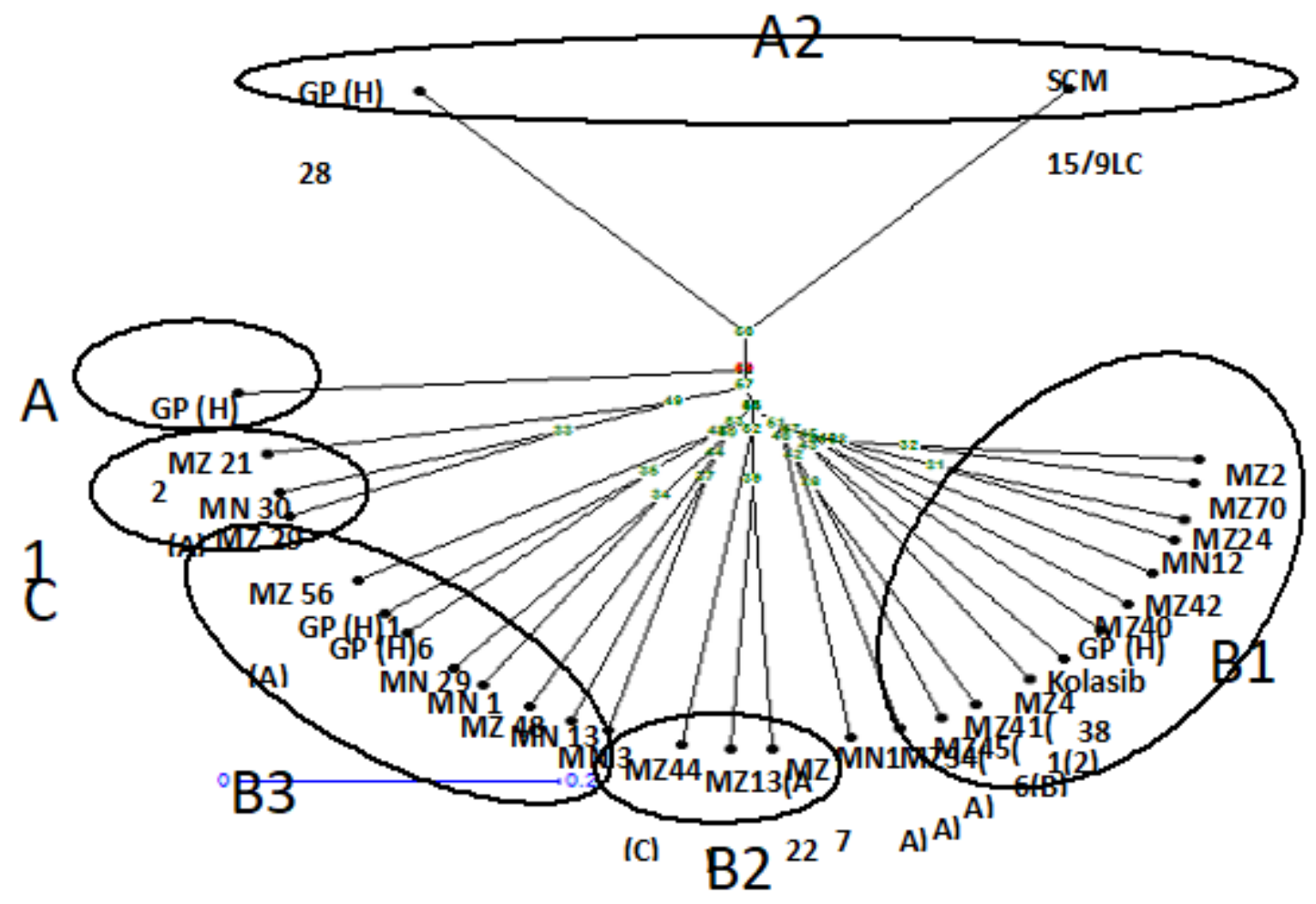

Figure 3

Cluster analysis revealed by 52 SSRs depicting genetic relationship among 30 lines. A, B and C indicate the major cluster, whereas 1, 2 and 3 indicate sub- clusters within each major cluster.

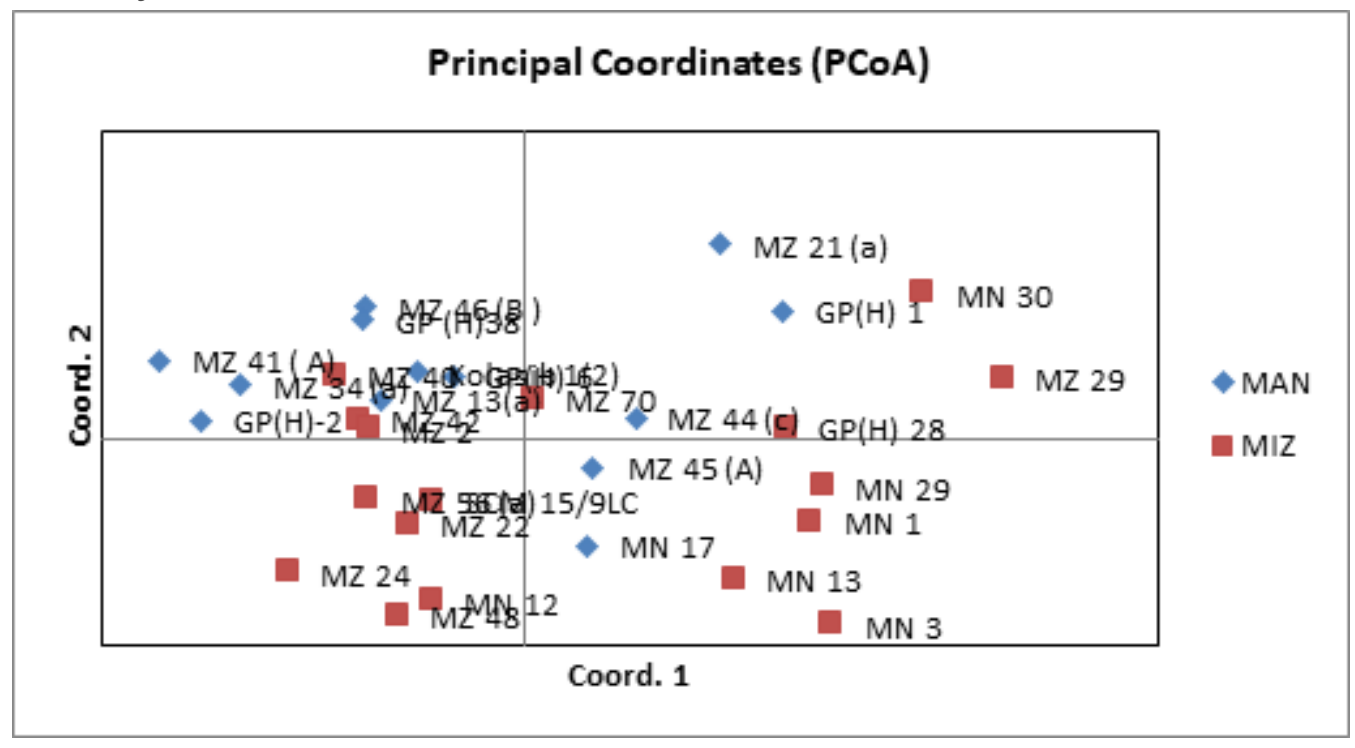

Figure 4

Two dimensional PCoA display of 30 genotypes based on 52 SSR markers. Coord 1 and Coord 2 represent first and second coordinates, respectively. The two PCoA axes accounted for $9.82 \%$ and $8.23 \%$ of the genetic variation among populations. 

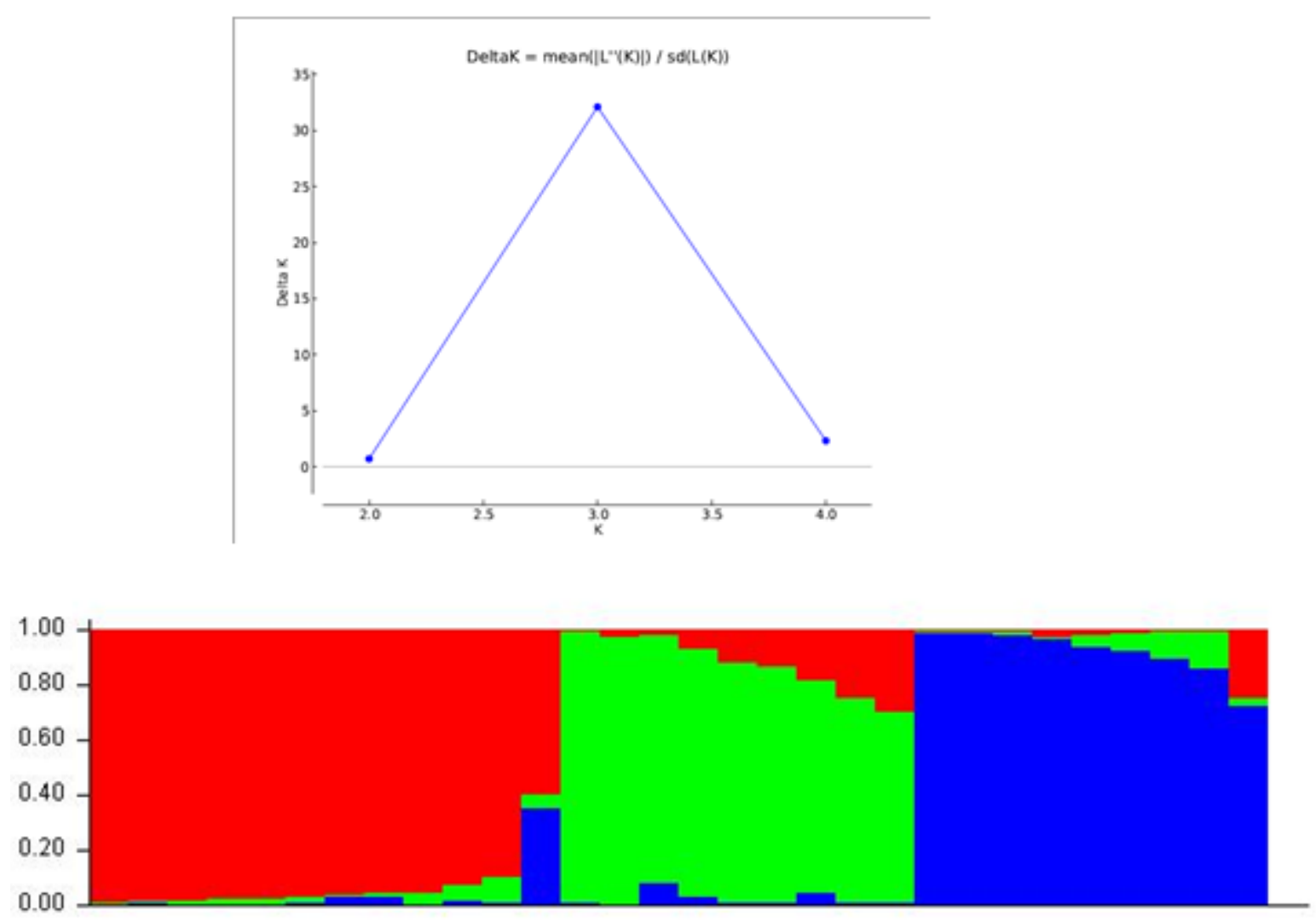

Figure 5

Population structure of 30 genotypes based on 52 SSR markers and graph of estimated membership fraction for $\mathrm{K}=3$.

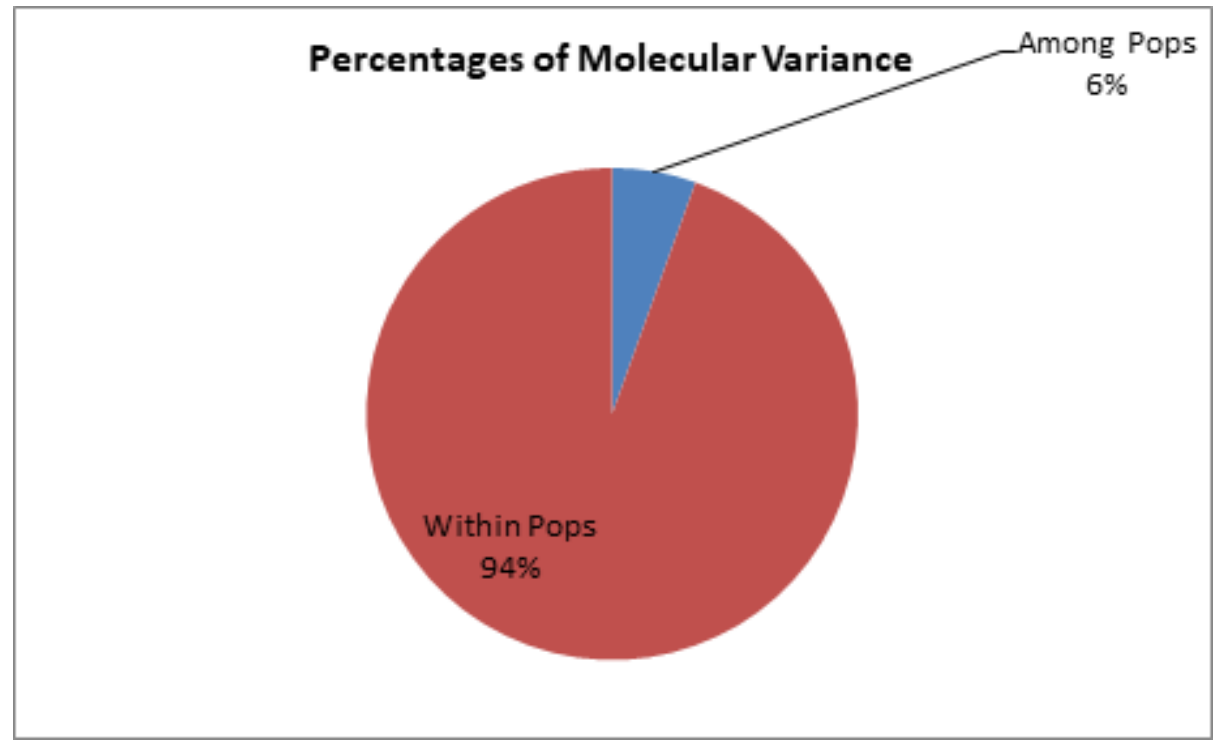

Figure 6

Analysis of molecular variance (AMOVA) of 30 genotypes based on 52 SSR markers 


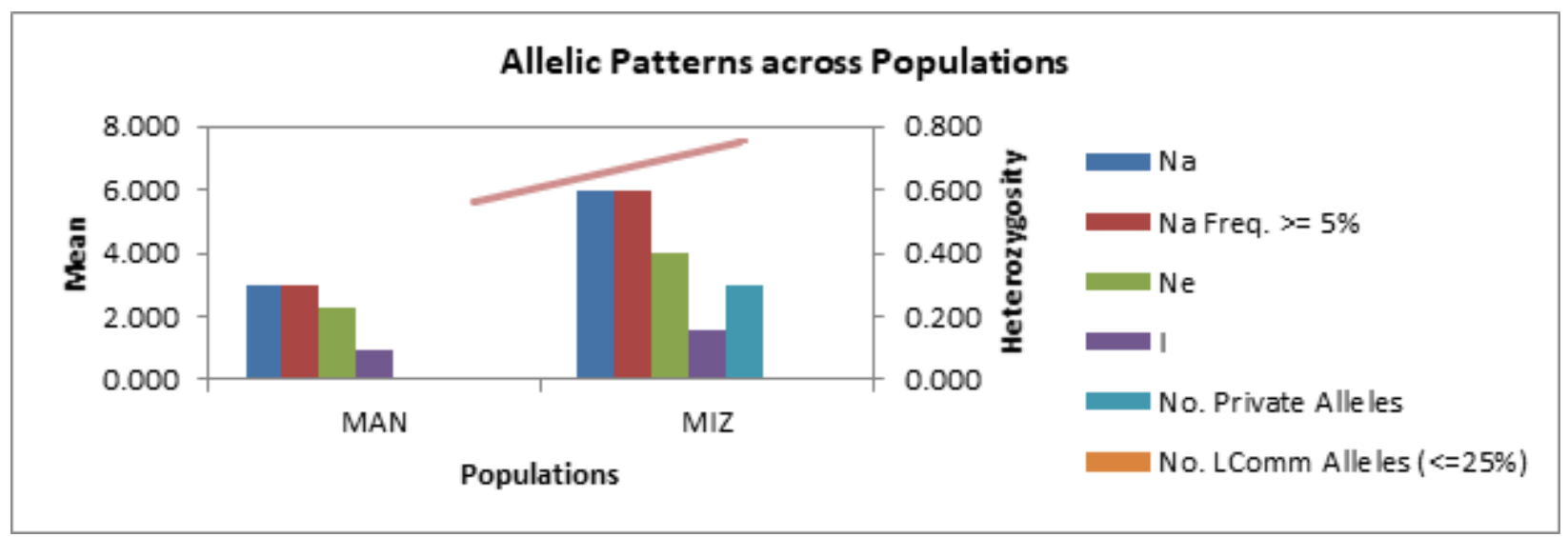

\section{Figure 7}

Graph showing allelic patterns across populations 